Article

\title{
Application and Mechanism of Sludge-Based Activated Carbon for Phenol and Cyanide Removal from Bio-Treated Effluent of Coking Wastewater
}

\author{
Yali Liu *, Han Cheng and Yueting He \\ School of Civil Engineering, Nanjing Forestry University, Nanjing 210037, China; deji1116@163.com (H.C.); \\ hyt18994113396@163.com (Y.H.) \\ * Correspondence: lylszgc@njfu.edu.cn; Tel.: +86-157-2062-8696
}

Received: 9 December 2019; Accepted: 6 January 2020; Published: 8 January 2020

\begin{abstract}
The toxic pollutants phenol and cyanide in the bio-treated effluent of coking wastewater still need advanced treatment to meet environmental requirements. In this study, activated carbon prepared from municipal sludge and bamboo waste (SBAC) was used for simultaneous adsorption of phenol and cyanide from bio-treated effluent of coking wastewater. The results showed that the optimum removal efficiencies of volatile phenol $(69.7 \%)$ and total cyanide $(80.1 \%)$ were observed at a SBAC dosage of $8 \mathrm{~g} / \mathrm{L}$, a pH value of 8.0 , and a contact time of $80 \mathrm{~min}$. The physical and chemical properties of SBAC were analyzed using Brunauer-Emmett-Teller (BET) surface area $\left(\mathrm{S}_{\mathrm{BET}}\right)$, scanning electron microscopy (SEM), and Fourier transform infrared (FTIR) spectroscopy. SBAC had high $\mathrm{S}_{\mathrm{BET}}$ $\left(289.58 \mathrm{~m}^{2} / \mathrm{g}\right)$ and rich mesoporous structure (average pore diameter of $3.688 \mathrm{~nm}$ ), and carboxylic groups on SBAC surfaces were enhanced due to the addition of bamboo waste. In addition, a kinetic model of pseudo-first-order fitted well with the experimental data of volatile phenol, while the adsorption of total cyanide onto the SBAC was better described by a pseudo-second-order kinetic model.
\end{abstract}

Keywords: activated carbon; adsorption kinetics; coking wastewater; municipal sludge

\section{Introduction}

In China, approximately 31.2 million tons of coking wastewater were produced from coal gas purification, coal coking, and the by-products recovery process of coking in 2017 [1]. Coking wastewater contains a large amount of organic pollutants, such as phenol and cyanide, which are highly toxic to both human and aquatic life even at low concentrations [2]. Therefore, it is critical to treat coking wastewater before it is discharged into the environment.

To date, numerous methods have been developed and applied to coking wastewater treatment [3-5], however, biological technologies are still widely used in China because they are eco-friendly methods for degrading organic pollutants into harmless substances $[5,6]$. It is reported that almost $95-98 \%$ of the organics in coking wastewater can be removed by biological degradation, but the phenol and cyanide contents in the bio-treated effluent still need further treatment to meet strict environmental requirements [1]. Therefore, filtration, coagulation, adsorption, and ozonation are used in the advanced treatment of coking wastewater after biological treatments [6-10]. Adsorption with activated carbon (AC) has been considered one of the most attractive techniques due to its simplicity and high removal performance [11,12]. However, the application of commercial AC in wastewater treatment is limited by its high-cost and non-renewable nature, therefore, many efforts have recently been made to prepare AC from renewable, abundant, and low-cost biomass [13-15]. For example, Singh et al. [15] used copper-impregnated coconut shell AC (Cu-CSAC) in a binary aqueous solution of phenol and cyanide, 
and the results showed that the optimal adsorption efficiencies for phenol (71.43\%) and cyanide (86.8\%) were observed at the temperature of $30^{\circ} \mathrm{C}$, the $\mathrm{pH}$ of 8 , and the adsorbent dose of $40 \mathrm{~g} / \mathrm{L}$.

Sludge is an inevitable by-product of municipal wastewater treatment plants (WWTPs). About 13 million tons (dry weight) of municipal sludge (MS) were produced in China in 2016 [16]. Preparation of AC from MS by pyrolysis/activation is a promising method for the sustainable management of MS, since MS is a carbon-rich, renewable, and readily accessible resource [12,17]. Nevertheless, the adsorption capacities of sludge-based AC (SAC) to contaminants are usually low due to the relatively high ash and inorganics in the MS [18]. Therefore, a wide variety of agricultural wastes, nuts, and plant leaves have been added into MS to improve its surface area, internal pore structure, and the chemical functional groups present on its surface $[19,20]$. Recent research has found that bamboo waste (BW) is a promising type of additive in the pyrolysis of MS because of its high lignocellulose content and specific morphological properties [21,22]. The hemicellulose and cellulose in BW are pyrolyzed to produce tar at $220-315{ }^{\circ} \mathrm{C}$ and $315-400{ }^{\circ} \mathrm{C}$, respectively [23], and some tars are continuously decomposed above $400^{\circ} \mathrm{C}$ into pyrolytic gas, promoting the formation of micropores [21]. Moreover, the AC prepared from BW has expanded carbon nanotubes and rich aromatic structures [22]. Currently, SAC has showed potential in removing metals, phenol, or cyanide from single or binary aqueous solutions [24]. However, the utilization of SAC for the co-adsorption of phenol and cyanide from real wastewater has not been reported yet.

Consequently, in this study, the AC produced from MS and BW (SBAC) was used for the simultaneous adsorption of volatile phenol and total cyanide from bio-treated effluent of real coking wastewater. The optimal values for operational parameters such as SBAC dosage, initial $\mathrm{pH}$, and contact time for efficient adsorption of phenol and cyanide in coking wastewater were investigated. Simultaneously, the adsorption mechanism of phenol and cyanide was determined by analyzing the physical and chemical properties of SBAC using scanning electron microscopy (SEM) and Fourier transform infrared spectrometer (FTIR). Additionally, the adsorption of phenol and cyanide onto SBAC was evaluated using adsorption kinetic models.

\section{Materials and Methods}

\subsection{Precursor of $S B A C$}

The MS used in this study was collected from a dewatering room of the Qiaobei WWTP in Nanjing, China. The BW was obtained from a furniture factory in Nanjing, China. The characteristics of MS and BW are shown in Table 1 . The MS and BW were dried to constant weight at $105^{\circ} \mathrm{C}$ using a drying oven (DGG-9030A, Donglu, Shanghai, China) and then crushed and sieved to a size below 80-mesh. Finally, these two powders were separately packed in sealed plastic bags and stored in a desiccator until use.

Table 1. Characteristics of municipal sludge (MS) and bamboo waste (BW).

\begin{tabular}{ccccccc}
\hline Parameters & $\begin{array}{c}\text { Volatile } \\
\text { Solids (VS) } \\
(\mathbf{d w} \%)\end{array}$ & Ash (dw \%) & $\begin{array}{c}\text { Water } \\
\text { Content } \\
(\mathbf{w w} \%)\end{array}$ & $\mathbf{C ~ ( d w ~ \% ) ~}$ & H (dw \%) & N (dw \%) \\
\hline MS & 62.01 & 37.99 & 78.86 & 26.5 & 6.24 & 4.08 \\
BW & 98.64 & 1.36 & 9.94 & 48.5 & 3.35 & 0.75 \\
\hline
\end{tabular}

dw: dry weight. ww: wet weight.

\subsection{Preparation of $S B A C$}

The dry MS and BW were mixed well in a stainless steel reactor with mass ratio of 2:1, and then soaked in $5 \mathrm{~mol} / \mathrm{L}$ of $\mathrm{ZnCl}_{2}$ solution $\left(\mathrm{ZnCl}_{2}\right.$ : raw material $\left.=3: 1, w / w\right)$ for $24 \mathrm{~h}$. Next, the mixture was centrifuged at $1176 \times g$ for $3 \mathrm{~min}$. Afterwards, the sediment was dried at $105^{\circ} \mathrm{C}$ for $12 \mathrm{~h}$, carbonized at $550{ }^{\circ} \mathrm{C}$ for $30 \mathrm{~min}$ in a resistance furnace (SX-12-10, Xinyi, Shanghai, China), and cooled to room temperature overnight. Next, the carbonized product was immersed in $1.0 \mathrm{~mol} / \mathrm{L} \mathrm{HCl}$ for $5 \mathrm{~min}$ at 
room temperature, and the above step was repeated three times. Finally, the product was rinsed to neutral $\mathrm{pH}$ with deionized water, dried, and pulverized to below 80-mesh to obtain SBAC.

The preparation steps of SAC were similar to that of SBAC, except that no BW was added to the MS.

\subsection{Characteristics of SBAC}

The porosity and surface area of SAC and SBAC samples were measured by a surface area pore analyzer (Micrometrics, ASAP2020, Norcross, GA, USA). The Brunauer-Emmett-Teller (BET) surface area $\left(\mathrm{S}_{\mathrm{BET}}\right)$ was calculated by use of the BET equation. The total pore volume $\left(\mathrm{V}_{\mathrm{T}}\right)$ was determined at relative pressure of 0.995 , and the micropore volume $\left(\mathrm{V}_{\text {mic }}\right)$ was analyzed by the de Boer method [25]. The average pore diameter $\left(\mathrm{D}_{\mathrm{P}}\right)$ of the SBAC was calculated using the equation $4 \mathrm{~V}_{\mathrm{T}} / \mathrm{S}_{\mathrm{BET}}$ [26].

The surface morphology of SAC and SBAC was measured by a SEM microscope (QUANTA 200, FEI, Hillsboro, OR, USA). The surface functional groups on the SAC and SBAC were evaluated with a FTIR spectrometer (IR-360, Nicolet, Madison, WI, USA), and the spectra were obtained in a wavelength rang of $400-4200 \mathrm{~cm}^{-1}$.

\subsection{Adsorption Tests}

Adsorption tests of SBAC were performed in three trials, using coking wastewater as adsorbate. The coking wastewater was taken from the bio-treated effluent in Shougang Jingtang Iron and Steel Co., Ltd. (Tangshan, China). The characteristics of the wastewater are summarized in Table 2. The coking wastewater was stored at $4{ }^{\circ} \mathrm{C}$ to avoid any changes in physical and chemical properties before use.

Table 2. Characteristics of coking wastewater.

\begin{tabular}{cc}
\hline Parameters & Coking Wastewater \\
\hline Chemical oxygen demand (COD) $(\mathrm{mg} / \mathrm{L})$ & $2457.6 \pm 125.4$ \\
Ammonia nitrogen $(\mathrm{mg} / \mathrm{L})$ & $316.3 \pm 24.2$ \\
Total cyanide $(\mathrm{mg} / \mathrm{L})$ & $35.4 \pm 1.5$ \\
Volatile phenol $(\mathrm{mg} / \mathrm{L})$ & $227.5 \pm 7.6$ \\
Suspended solids $(\mathrm{SS})(\mathrm{mg} / \mathrm{L})$ & $76.9 \pm 6.5$ \\
$\mathrm{pH}$ & $8.1 \pm 0.8$ \\
\hline
\end{tabular}

Operational parameters are important variables affecting the adsorption process. The $\mathrm{pH}$ influences the surface charge and functional groups of absorbent, as well as the ionization capacity of the adsorbate [27]. Contact time is another important parameter to determine the equilibrium time and kinetics of adsorption process [12]. Larger surface area and more binding sites were found with increase of adsorbent dosage, which directly affects the removal efficiency of absorbate [28]. Therefore, the effects of different adsorption parameters such as initial pH (4-10), contact time (0-120 min), and adsorbent dosage (1-12 g/L) on adsorption process were investigated. All adsorption experiments were performed in 250.0-mL conical flasks, in each of which $100.0 \mathrm{~mL}$ of coking wastewater and different amounts of SBAC were placed. The solutions were shaken at $100 \mathrm{rpm}$ using a thermostatic shaker incubator (SHZ-82, Changzhou Guohua Electric Appliance Co., Ltd., Changzhou, China). The initial $\mathrm{pH}$ values were adjusted by adding $1.0 \mathrm{M}$ of hydrochloric acid or $1.0 \mathrm{M}$ of sodium hydroxide solution. At the end of each experiment, samples were filtered through 0.45- $\mu \mathrm{m}$ Millipore HA membranes (Millipore, Billerica, MA, USA), and the concentrations of volatile phenol and total cyanide in the filtrates were determined.

All experiments were conducted in triplicate, and the average and standard deviation values were recorded. 


\subsection{Analytical Methods}

The COD, ammonia nitrogen, water content, VS, and SS were measured according to standard methods [29]. The $\mathrm{pH}$ was measured by a pH meter (PHS-3C, Leici, Shanghai, China). The elemental composition of the MS and BW $(\mathrm{C}, \mathrm{H}$, and $\mathrm{N})$ was determined by an automatic elemental analyzer (Vario EL cube, Elementar, Hanau, Germany). The concentrations of volatile phenol and total cyanide in the coking wastewater were determined by 4 -aminoantipyrine (20, pp. 1014) and pyridine-barbituric acid (20, pp. 607) spectrophotometry, respectively [29].

The removal efficiency $(E, \%)$ and the equilibrium adsorption capacity $\left(q_{e}, \mathrm{mg} / \mathrm{g}\right)$ of SBAC on volatile phenol and total cyanide were calculated using Equations (1) and (2):

$$
\begin{gathered}
E=\frac{C_{0}-C_{e}}{C_{0}} \times 100 \% \\
q_{e}=\frac{\left(C_{0}-C_{e}\right) \times V}{W}
\end{gathered}
$$

where $q_{e}$ represents the amount of pollutants adsorbed in mg per $g$ of SBAC at equilibrium conditions; $C_{0}$ and $C_{e}$ are initial and equilibrium concentrations of volatile phenol or total cyanide $(\mathrm{mg} / \mathrm{L})$, respectively; $V$ is the volume of coking wastewater (L); and $W$ is the weight of SBAC (g).

\section{Results and Discussion}

\subsection{Characterizations of the SBAC}

\subsubsection{BET Surface Area and Pore Structure}

Nitrogen $\left(\mathrm{N}_{2}\right)$ adsorption-desorption isotherms of SAC and SBAC are shown in Figure 1. According to the International Union of Pure and Applied Chemistry (IUPAC) classification, the shape of isotherms and hysteresis loops were classified as Type II with H3 hysteresis, which indicated that the SAC and SBAC samples had mesoporous structures [30]. Simultaneously, it can be seen that the adsorbed volume of SBAC was almost twice that of the SAC, indicating that SBAC had a richer mesoporous structure than SAC.
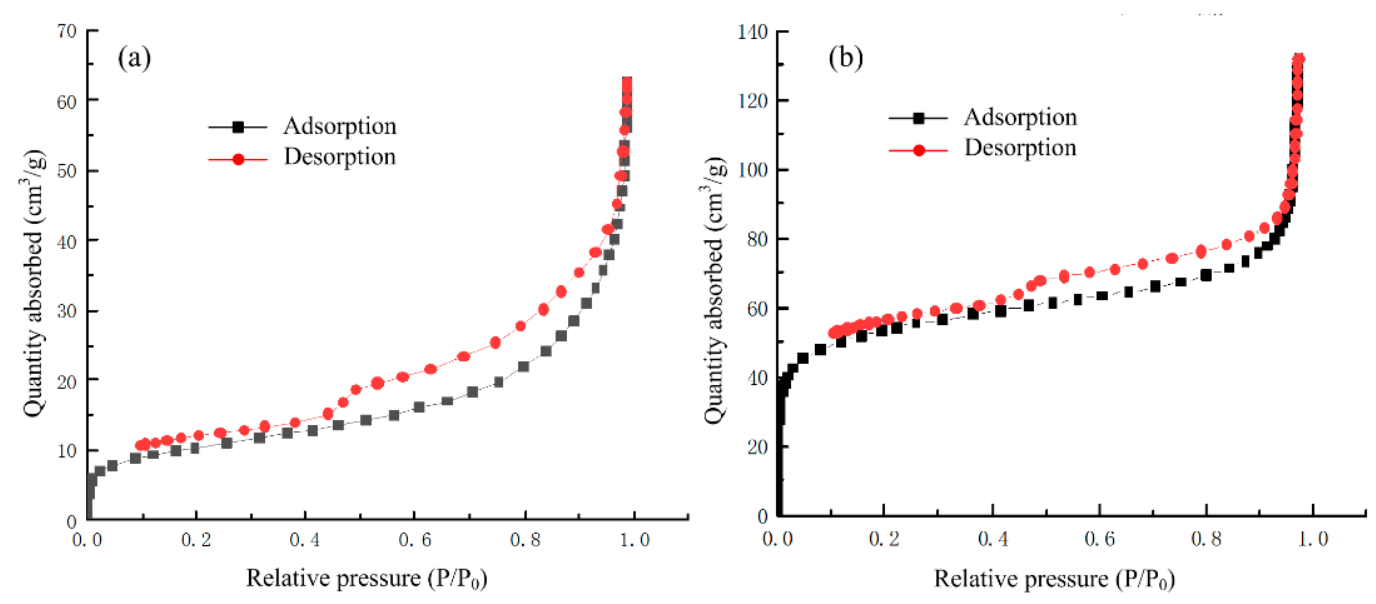

Figure 1. $\mathrm{N}_{2}$ adsorption-desorption isotherm of (a) SAC and (b) SBAC. 
The pore structure characteristics of SAC and SBAC are listed in Table 3. The $\mathrm{D}_{\mathrm{p}}$ of SBAC was $3.688 \mathrm{~nm}$, which was much lower than that of SAC $(10.941 \mathrm{~nm})$. The $\mathrm{S}_{\mathrm{BET}}$ of the SBAC was found to be $289.578 \mathrm{~m}^{2} / \mathrm{g}$ with a $\mathrm{V}_{\mathrm{T}}$ of $0.267 \mathrm{~cm}^{3} / \mathrm{g}$, which were almost 4.08 and 1.38 times higher than that of the SAC, respectively. It is argued that the addition of BW was effective in enhancing the surface area and pore volume by converting macropores or mesopores to micropores. As previously reported, when the temperature is above $400{ }^{\circ} \mathrm{C}$, some tar produced from hemicellulose/cellulose in $\mathrm{BW}$ is broken down and converted into pyrolytic gas, thereby promoting the formation of pores [21]. Therefore, the addition of BW to improve carbon content in MS was the most likely reason for the significant increase in the surface area and pore volume of SBAC.

Table 3. Characteristics of porous structure of SAC and SBAC.

\begin{tabular}{cccccc}
\hline Samples & $\mathbf{S}_{\text {BET }}\left(\mathbf{m}^{2} / \mathbf{g}\right)$ & $\begin{array}{c}\text { Micropore Surface } \\
\text { Area }\left(\mathbf{m}^{2} / \mathbf{g}\right)\end{array}$ & $\mathbf{V}_{\mathbf{T}}\left(\mathbf{c m}^{3} / \mathbf{g}\right)$ & $\mathbf{V}_{\mathbf{m i c}}\left(\mathbf{c m}^{3} / \mathbf{g}\right)$ & $\mathbf{D}_{\mathbf{p}}(\mathbf{n m})$ \\
\hline SAC & 70.921 & 18.568 & 0.194 & 0.016 & 10.941 \\
SBAC & 289.578 & 70.523 & 0.267 & 0.049 & 3.688 \\
\hline
\end{tabular}

\subsubsection{SEM Analyses}

SEM analysis results of the SAC and SBAC samples are shown in Figure 2. Unlike the flaky and massive particles on the surface of the SAC, the SBAC exhibited a more irregular and looser surface morphology. These surface features might provide sufficient diffusion spaces for contaminants in the coking wastewater.

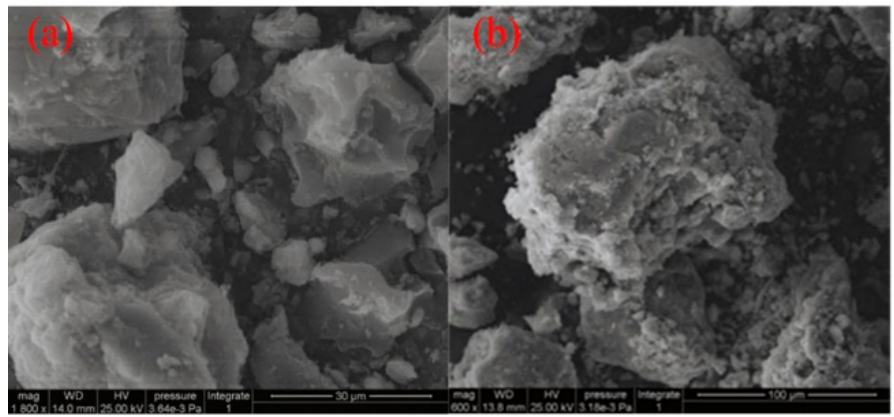

Figure 2. SEM images of (a) SAC and (b) SBAC.

\subsubsection{FTIR Analysis}

It is well known that the adsorption performance of $\mathrm{AC}$ is strongly affected by functional groups such as carboxyl, carbonyl, phenolic hydroxyl, and lactones on the surface [30,31]. FTIR spectra of the SAC and SBAC samples are shown in Figure 3. The broad absorption band in the range of $3300-3600 \mathrm{~cm}^{-1}$ is ascribed to the O-H stretching vibrations, which correspond to associated peaks of hydroxyl groups from phenols and alcohols [19]. The distinctive peak observed at $1624 \mathrm{~cm}^{-1} \mathrm{can} \mathrm{be}$ attributed to the $\mathrm{C}=\mathrm{O}$ and $\mathrm{C}=\mathrm{C}$ vibration of carbonyl in carboxylic or ester groups [32]. The absorption peak at $1383 \mathrm{~cm}^{-1}$ seems to be due to the lactone groups [33]. The relatively intense band at $1042 \mathrm{~cm}^{-1}$ can be attributable to alcohol groups $(\mathrm{C}-\mathrm{OH})$ [32]. In addition, the peaks at $465 \mathrm{~cm}^{-1}$ represented the $\mathrm{C}-\mathrm{H}$ stretching vibration [33]. In this study, the addition of BW led to an increase of oxygen-containing functional groups $(\mathrm{C}-\mathrm{OH}, \mathrm{O}-\mathrm{H}$, and $\mathrm{C}=\mathrm{O})$, which might contribute to the adsorption of total cyanide. 


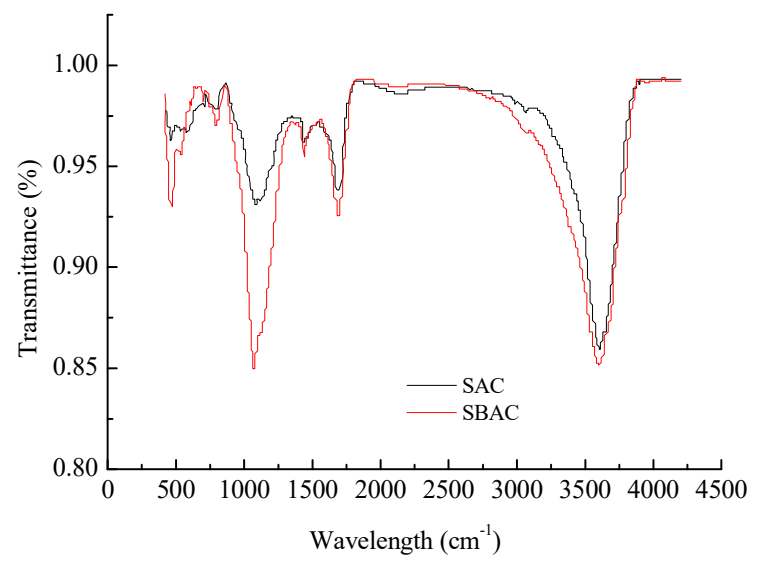

Figure 3. FTIR of SAC and SBAC samples.

\subsection{Adsorption Performances of SBAC}

\subsubsection{Effect of Initial $\mathrm{pH}$}

The effect of initial $\mathrm{pH}$ on the removal efficiencies of volatile phenol and total cyanide in coking wastewater was assessed at a SBAC dosage of $8 \mathrm{~g} / \mathrm{L}$ and a contact time of $80 \mathrm{~min}$. As shown in Figure 4 , the removal efficiencies of volatile phenol increased at first and then decreased with the increase of $\mathrm{pH}$, and the maximal removal efficiency $(71.3 \%)$ was observed at $\mathrm{pH} 7.0$. On the other hand, as the $\mathrm{pH}$ increased from 4.0 to 8.0, the removal efficiencies of total cyanide increased rapidly from $27.9 \%$ to $80.1 \%$, and then maintained relative stability. Based on the above results, the optimal $\mathrm{pH}$ was determined to be 8.0 for simultaneous removal of volatile phenol and total cyanide in coking wastewater.

The adsorption of AC on phenol and cyanide may not only be related to the pore structure, but also affected by the types of functional groups and the chemical nature of absorbate. Changes in the $\mathrm{pH}$ might alter the electron-withdrawing effect of oxygen-containing functional groups on the surface of SBAC, thereby changing the $\pi-\pi$ interaction between the pollutant molecules [34]. In addition, under strong alkaline conditions, the enhanced competition of ammonia nitrogen with phenols and cyanide might be another cause of the decrease in removal efficiency.

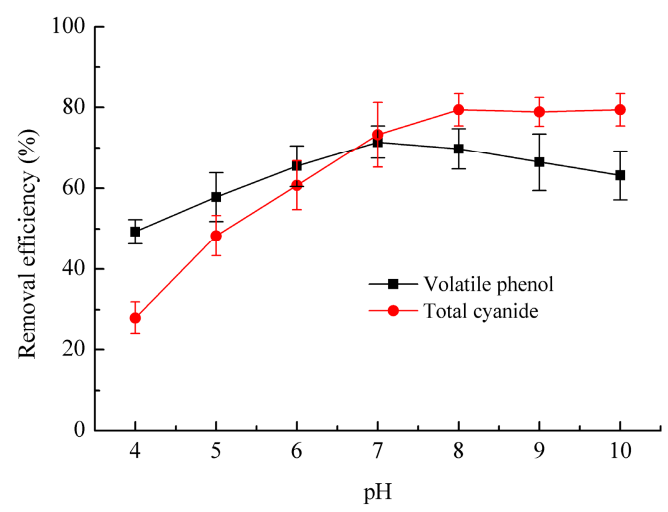

Figure 4. Effects of initial $\mathrm{pH}$ on the removal efficiencies of volatile phenol and total cyanide. Error bars represent the range of data from duplicate experiments.

\subsubsection{Effect of Contact Time}

The effect of contact time on the removal efficiencies of volatile phenol and total cyanide in coking wastewater was investigated at a SBAC dosage of $8 \mathrm{~g} / \mathrm{L}$, a pH of 8.0 , and a temperature of $25^{\circ} \mathrm{C}$. It can be seen from Figure 5 that in the first $60 \mathrm{~min}$, the removal efficiencies of volatile phenol and total 
cyanide increased significantly, and remained relatively stable after $80 \mathrm{~min}$. The maximal removal efficiencies of volatile phenol and total cyanide reached $69.7 \%$ and $80.1 \%$, respectively. This might be owing to the fact that there were more available active sites on the surface of SBAC in the initial stage of adsorption, and, simultaneously, a higher concentration gradient between wastewater and SBAC was more conducive to the mass transfer of phenol and cyanide to SBAC [12]. However, with the passage of time, the vacant sites and active functional groups on the SBAC reached saturation, leading to the termination of phenol and cyanide adsorption [34].

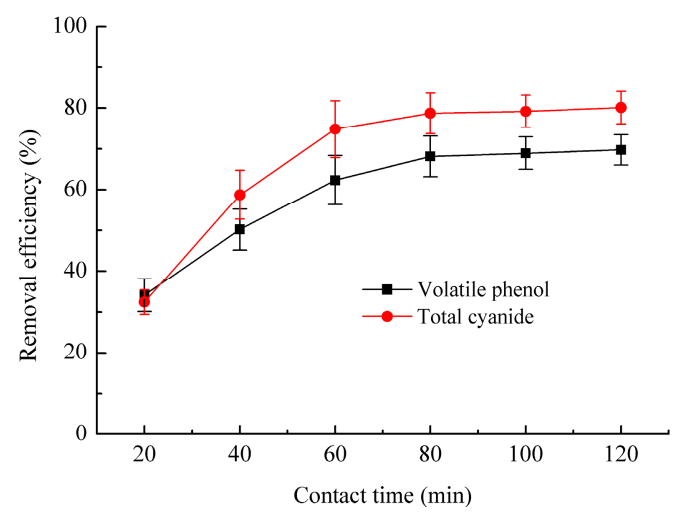

Figure 5. Effects of contact time on the removal efficiencies of volatile phenol and total cyanide. Error bars represent the range of data from duplicate experiments.

\subsubsection{Effect of SBAC Dosage}

The effect of SBAC dosages (1-12 g/L) on the volatile phenol and total cyanide removal in coking wastewater was evaluated at a contact time of $80 \mathrm{~min}$, a $\mathrm{pH}$ of 8.0 , and a temperature of $25^{\circ} \mathrm{C}$. The result is shown in Figure 6. It can be seen that the removal efficiencies of volatile phenol and total cyanide increased gradually to $69.7 \%$ and $80.1 \%$, respectively, with SBAC dosage increasing from 1 to $8 \mathrm{~g} / \mathrm{L}$. This phenomenon can be explained as follows: with the increase of SBAC dosage, the provided adsorption surface area and active sites were enhanced [35]. However, no significant changes in volatile phenol and total cyanide were observed when the SBAC dosage exceeded $8 \mathrm{~g} / \mathrm{L}$, probably due to the fact that at high SBAC dosage the overlap of some active sites not only reduced the surface area for adsorption, but also decreased the odds of point contacts between SBAC and contaminants [15]. It was also found that the SBAC dosage in this study was higher than other adsorption studies of only phenol or cyanide, which might be attributed to the competitive adsorption of other pollutants in the coking wastewater.

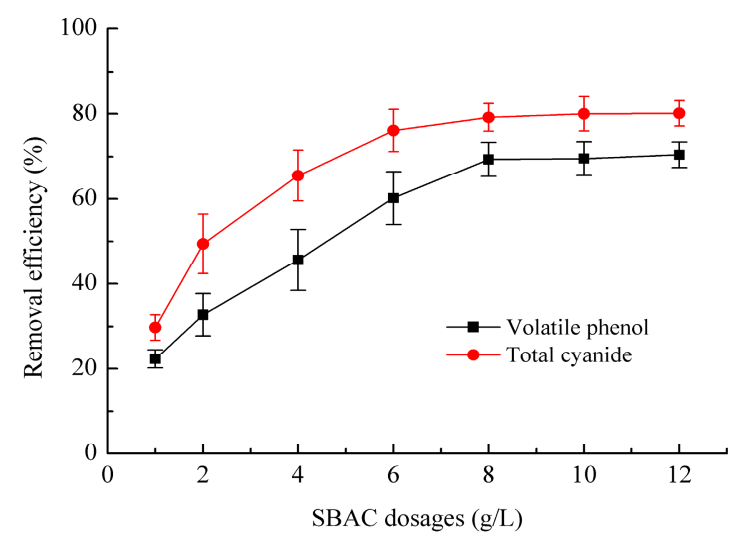

Figure 6. Effects of SBAC dosages on the removal efficiencies of volatile phenol and total cyanide. Error bars represent the range of data from duplicate experiments. 


\subsection{Kinetics of Volatile Phenol and Total Cyanide}

In this study, pseudo-first-order [36] and pseudo-second-order kinetic models [37] were used for the experimental data to evaluate the adsorption mechanism of volatile phenol or total cyanide onto the SBAC. The linear form of pseudo-first and pseudo-second order kinetic models are shown as Equations (3) and (4), respectively.

$$
\begin{gathered}
\ln \left(q_{e}-q_{t}\right)=\ln q_{e}-k_{1} t \\
\frac{t}{q_{t}}=\frac{1}{k_{2} q_{e}^{2}}+\frac{t}{q_{e}}
\end{gathered}
$$

where $q_{t}$ is the adsorption amount $(\mathrm{mg} / \mathrm{g})$ of volatile phenol or total cyanide at time $t(\mathrm{~min})$, and the $k_{1}$ and $k_{2}$ are the rate constants of the pseudo-first-order $(1 / \mathrm{min})$ and pseudo-second-order adsorption $(\mathrm{g} /(\mathrm{mg} \cdot \mathrm{min}))$, respectively.

The average relative error $(A R E)$ between the experimental data $\left(q_{e}^{\exp }\right)$ and calculated values $\left(q_{e}^{\text {cal }}\right)$ was used to validate the goodness of fit of the kinetic models [15]. ARE is calculated according to Equation (5):

$$
\operatorname{ARE}(\%)=100 / N \times \sqrt{\sum_{i=1}^{P}\left(\frac{q_{e, i}^{\exp }-q_{e, i}^{c a l}{ }^{2}}{q_{e, i}^{\exp }}\right)}
$$

where $N$ is the number of observations in the kinetic experiment, and $P$ is the number of parameters in the regression model. The smaller ARE values indicate more accurate estimation of $q_{e}$ [15].

The linear form of the pseudo-first-order and pseudo-second-order kinetic models for volatile phenol and total cyanide on the SBAC is presented in Figure 7 and Table 4. For the volatile phenol adsorption, both pseudo-first-order and pseudo-second-order kinetic models fitted well with experimental data, and the corresponding correlation coefficients $\left(R^{2}\right)$ were 0.974 and 0.991 , respectively. However, the calculated $q_{e}$ values $\left(q_{e}^{\text {cal }}\right)$ obtained from the pseudo-first-order model $(20.46 \mathrm{mg} / \mathrm{g})$ were closer to the experimental value $(20.02 \mathrm{mg} / \mathrm{g})$ than the value determined by the pseudo-second-order model $(25.38 \mathrm{mg} / \mathrm{g})$. This indicated that the pseudo-first-order equation might be more suitable for describing the mechanism of phenol-SBAC interactions. For the total cyanide adsorption, the $R^{2}$ of pseudo-first-order was higher than that of pseudo-second-order, but the $q_{e}$ value determined from the pseudo-second-order model was more consistent with the experimental value. Therefore, it is proposed that the pseudo-second-order kinetic model should be used to describe the adsorption of cyanides onto SBAC, which is in line with a previous study [34].
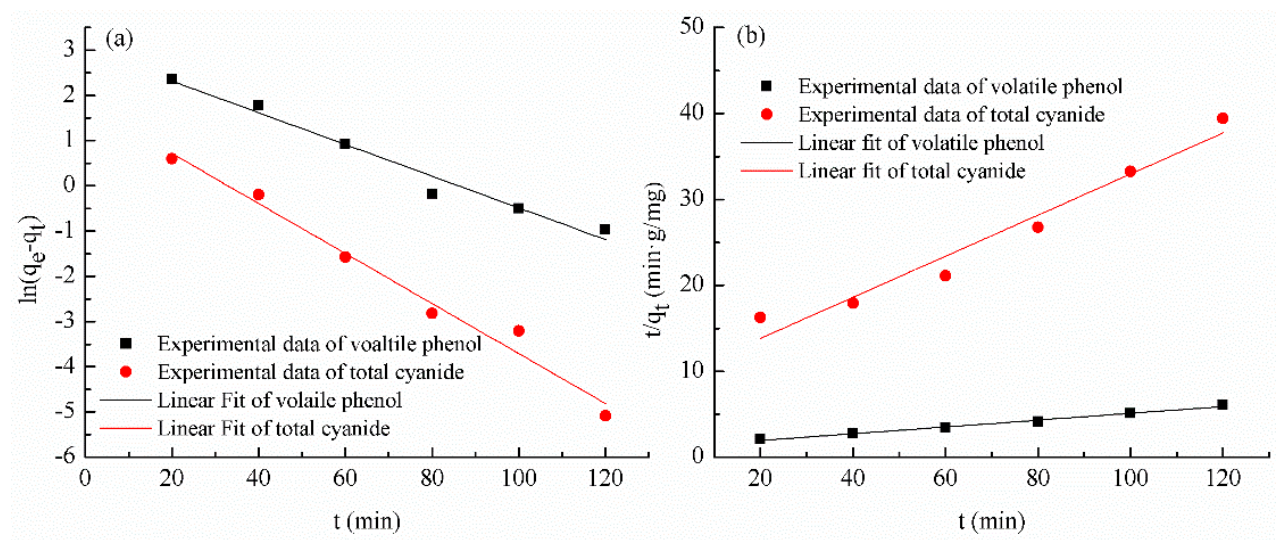

Figure 7. (a) Pseudo-first-order and (b) pseudo-second-order adsorption kinetics for volatile phenol and total cyanide adsorption onto SBAC. 
Table 4. Parameters of kinetic modeling of the adsorption of volatile phenol and total cyanide onto SBAC.

\begin{tabular}{cccccccccc}
\hline \multirow{2}{*}{$\begin{array}{c}\text { Kinetic Modeling } \\
\text { Parameters }\end{array}$} & \multicolumn{4}{c}{ Pseudo-First-Order } & \multicolumn{3}{c}{ Pseudo-Second-Order } & \multirow{2}{*}{$\boldsymbol{q}_{\mathrm{e}}^{\text {exp }}$} \\
\cline { 2 - 10 } & $\boldsymbol{k}_{1}$ & $\boldsymbol{q}_{\boldsymbol{e}}^{\text {cal }}$ & $\boldsymbol{R}^{2}$ & $\boldsymbol{A R E}$ & $\boldsymbol{k}_{2}$ & $\boldsymbol{q}_{\boldsymbol{e}}^{\text {cal }}$ & $\boldsymbol{R}^{2}$ & $\boldsymbol{A} \boldsymbol{R} E$ & \\
\hline Volatile phenol & 0.0351 & 20.46 & 0.9737 & 1.29 & 0.0013 & 25.38 & 0.9912 & 25.64 & 20.02 \\
Total cyanide & 0.0553 & 6.17 & 0.9804 & 89.26 & 0.0063 & 4.18 & 0.9605 & 28.22 & 3.26 \\
\hline
\end{tabular}

\subsection{Cost Analysis}

In this section, the cost of production per kilogram SBAC is roughly calculated based on raw material fees, reagent fees, water fees, and electricity fees. The one-time investment costs, depreciation costs, freight costs, and labor costs were not included. The industrial water and electricity costs, as well as sludge treatment compensation, were calculated according to the standard in Nanjing, China. The calculation results are described in Table 5. It can be seen that the cost per kilogram of SBAC production was about 0.840 USD, which is cheaper than commercial AC (2.0-2.2 USD $/ \mathrm{kg})$ [38]. According to gross cost estimate from previous literature, the cost of sludge-based adsorbents $(0.1-0.2 \mathrm{USD} / \mathrm{kg})$ is only $5-10 \%$ of commercial AC [39]. In this study, the data used for cost analysis are derived from laboratory studies, and the costs of SBAC production are expected to be reduced through large-scale production.

Table 5. Cost analysis of SBAC.

\begin{tabular}{cccc}
\hline Materials and Energy & Consumption & Unit Cost & Cost (USD) \\
\hline $\mathrm{ZnCl}_{2}$ (recovery rate of 70\%) & $0.315 \mathrm{~kg}$ & $1.227(\mathrm{USD} / \mathrm{kg})$ & 0.387 \\
$\mathrm{HCl}$ & $0.169 \mathrm{~kg}$ & $45.984(\mathrm{USD} / \mathrm{t})$ & 0.008 \\
Water & $51.240 \mathrm{~L}$ & $0.859(\mathrm{USD} / \mathrm{kg})$ & 0.044 \\
Electricity & $6.5 \mathrm{kWh}$ & $0.104(\mathrm{USD} / \mathrm{kWh})$ & 0.676 \\
$\mathrm{BW}$ & $0.562 \mathrm{~kg}$ & $0.359(\mathrm{USD} / \mathrm{kg})$ & 0.202 \\
By-product tar & $0.52 \mathrm{~kg}$ & $308.955(\mathrm{USD} / \mathrm{t})$ & -0.306 \\
Tludge treatment compensation & $7.460 \mathrm{~kg}$ & $22.992(\mathrm{USD} / \mathrm{t})$ & -0.171 \\
Total (USD/kg) & & & 0.840 \\
\hline
\end{tabular}

\section{Conclusions}

When SBAC was applied as absorbent for coking wastewater treatment, volatile phenol and total cyanide were rapidly adsorbed. For the highest removal efficiencies of volatile phenol $(69.7 \%)$ and total cyanide (80.1\%) in the coking wastewater, the optimized SBAC dosage was $8 \mathrm{~g} / \mathrm{L}$, the $\mathrm{pH}$ was 8.0, and the contact time was $80 \mathrm{~min}$. Due to the addition of BW, a high surface area $\left(289.578 \mathrm{~m}^{2} / \mathrm{g}\right)$ with the presence of a rich mesoporous structure might be the main reason for the adsorption of volatile phenol and total cyanide over the SBAC. Simultaneously, the increase of oxygen-containing functional groups ( $-\mathrm{OH}, \mathrm{C}=\mathrm{O}$ ) on the surface of SBAC might be more conducive to driving the chemisorption process of cyanide. In addition, the kinetic model of pseudo-first-order fitted well to the experimental data of volatile phenol, while the adsorption of total cyanide onto SBAC should be described by the pseudo-second-order kinetic model. The cost analysis based on experimental data indicated that the SBAC was more economical than commercial AC, and its production cost might be further reduced by mass production.

Author Contributions: Conceptualization: Y.L.; validation: Y.H. and H.C.; investigation: Y.H. and H.C.; data curation: H.C.; writing — original draft preparation: Y.L.; writing—review and editing: Y.L. All authors have read and agreed to the published version of the manuscript.

Funding: This work was financially supported by the Nanjing Forestry University Youth Innovation Fund (CX2017025), the National Natural Science Foundation of China (No. 51608272), and the Undergraduate Practical Innovation Training Program Project (2019NFUSPITP0487). 
Conflicts of Interest: The authors declare no conflict of interest.

\section{References}

1. Wei, C.; Wu, H.; Kong, Q.; Wei, J.; Feng, C.; Qiu, G.; Wei, C.; Li, F. Residual chemical oxygen demand (COD) fractionation in bio-treated coking wastewater integrating solution property characterization. J. Environ. Manag. 2019, 246, 324-333. [CrossRef]

2. Zhang, Y.; Wei, C.; Yan, B. Emission characteristics and associated health risk assessment of volatile organic compounds from a typical coking wastewater treatment plant. Sci. Total Environ. 2019, 693, 133417-133427. [CrossRef] [PubMed]

3. Martinkova, L.; Chmatal, M. The integration of cyanide hydratase and tyrosinase catalysts enables effective degradation of cyanide and phenol in coking wastewaters. Water Res. 2016, 102, 90-95. [CrossRef] [PubMed]

4. Razaviarani, V.; Zazo, J.A.; Casas, J.A.; Jaffe, P.R. Coupled fenton-denitrification process for the removal of organic matter and total nitrogen from coke plant wastewater. Chemosphere 2019, 224, 653-657. [CrossRef] [PubMed]

5. Ren, G.; Zhou, M.; Zhang, Q.; Xu, X.; Li, Y.; Su, P.; Paidar, M.; Bouzek, K. Cost-efficient improvement of coking wastewater biodegradability by multi-stages flow through peroxi-coagulation under low current load. Water Res. 2019, 154, 336-348. [CrossRef]

6. Sun, G.; Wan, J.; Sun, Y.; Li, H.; Chang, C.; Wang, Y. Enhanced removal of nitrate and refractory organic pollutants from bio-treated coking wastewater using corncobs as carbon sources and biofilm carriers. Chemosphere 2019, 237, 124520. [CrossRef] [PubMed]

7. Kumar, R.; Pal, P. A novel forward osmosis-nano filtration integrated system for coke-oven wastewater reclamation. Chem. Eng. Res. Des. 2015, 100, 542-553. [CrossRef]

8. Xie, R.; Wu, M.; Qu, G.; Ning, P.; Cai, Y.; Lv, P. Treatment of coking wastewater by a novel electric assisted micro-electrolysis filter. J. Environ. Sci. China 2018, 66, 165-172. [CrossRef]

9. Zhou, X.; Hou, Z.; Lv, L.; Song, J.; Yin, Z. Electro-Fenton with peroxi-coagulation as a feasible pre-treatment for high-strength refractory coke plant wastewater: Parameters optimization, removal behavior and kinetics analysis. Chemosphere 2020, 238, 124649. [CrossRef]

10. Pueyo, N.; Miguel, N.; Ovelleiro, J.L.; Ormad, M.P. Limitations of the removal of cyanide from coking wastewater by ozonation and by the hydrogen peroxide-ozone process. Water Sci. Technol. 2016, 74, 482-490. [CrossRef]

11. Zhou, H.; Wei, C.; Zhang, F.; Hu, Y.; Wu, H.; Kraslawski, A. A comprehensive evaluation method for sludge pyrolysis and adsorption process in the treatment of coking wastewater. J. Environ. Manag. 2019, 235, 423-431. [CrossRef] [PubMed]

12. Devi, P.; Saroha, A.K. Utilization of sludge based adsorbents for the removal of various pollutants: A review. Sci. Total Environ. 2017, 578, 16-33. [CrossRef] [PubMed]

13. Jing, Z.; Peng, Y.; He, R.; Xu, Y.; Yu, T.; Hu, J. Poplar leaves reclamation for porous granules and their application in nitrobenzene removal from aqueous solution. Desalin. Water Treat. 2016, 57, 449-458. [CrossRef]

14. Wang, Z. Efficient adsorption of dibutyl phthalate from aqueous solution by activated carbon developed from phoenix leaves. Int. J. Environ. Sci. Technol. 2015, 12, 1923-1932. [CrossRef]

15. Singh, N.; Balomajumder, C. Simultaneous removal of phenol and cyanide from aqueous solutionby adsorption onto surface modified activated carbon prepared fromcoconut shell. J. Water Process Eng. 2016, 9, 233-245. [CrossRef]

16. Liu, Y.; Kang, X.; Li, X.; Wang, Z.; Jing, Z. Performance and mechanism of sludge dewaterability enhanced by potassium ferrate pretreatment and calcium chloride addition. J. Water Reuse Desalin. 2017, 7, 136-141. [CrossRef]

17. Liu, G.; Lin, S.; Pile, L.S.; Fang, Z.; Wang, G.G. Effect of potassium permanganate and pyrolysis temperature on the biochar production from rice straw and suitability of biochars for heavy metal $(\mathrm{Cd} \& \mathrm{~Pb})$ immobilizaiton in paper sludge. Fresenius Environ. Bull. 2018, 27, 9008-9018.

18. Silva, T.L.; Cazetta, A.L.; Souza, P.S.C.; Zhang, T.; Asefa, T.; Almeida, V.C. Mesoporous activated carbon fibers synthesized from denim fabric waste: Efficient adsorbents for removal of textile dye from aqueous solutions. J. Clean. Prod. 2018, 171, 482-490. [CrossRef] 
19. Anisuzzaman, S.M.; Joseph, C.G.; Krishnaiah, D.; Bono, A.; Suali, E.; Abang, S.; Fai, L.M. Removal of chlorinated phenol from aqueous media by guava seed (Psidium guajava) tailored activated carbon. Water Resour. Ind. 2016, 16, 29-36. [CrossRef]

20. Castro, C.S.; Abreu, A.L.; Silva, C.L.T.; Guerreiro, M.C. Phenol adsorption by activated carbon produced from spent coffee grounds. Water Sci. Technol. 2011, 64, 2059-2065. [CrossRef]

21. Jin, J.; Wang, M.; Cao, Y.; Wu, S.; Liang, P.; Li, Y.; Zhang, J.; Zhang, J.; Wong, M.H.; Shan, S.; et al. Cumulative effects of bamboo sawdust addition on pyrolysis of sewage sludge: Biochar properties and environmental risk from metals. Bioresour. Technol. 2017, 228, 218-226. [CrossRef] [PubMed]

22. Tao, X.; Lou, L.; Luo, L.; Cao, R.; Duan, D.; Chen, Y. Effect of bamboo biochar on pentachlorophenol leachability and bioavailability in agricultural soil. Sci. Total Environ. 2012, 414, 727-731.

23. Al-Wabel, M.I.; Al-Omran, A.; El-Naggar, A.H.; Nadeem, M.; Usman, A.R.A. Pyrolysis temperature induced changes in characteristics and chemical composition of biochar produced from conocarpus wastes. Bioresour. Technol. 2013, 131, 374-379. [CrossRef] [PubMed]

24. Mu'azu, N.D.; Jarrah, N.; Zubair, M.; Alagha, O. Removal of Phenolic Compounds from Water Using Sewage Sludge-Based Activated Carbon Adsorption: A Review. Int. J. Environ. Res. Public Health 2017, 14, 1094. [CrossRef] [PubMed]

25. Schneider, P. Adsorption isotherms of microporous-mesoporous solids revisited. Appl. Catal. A Gen. 1995, 129, 157-165. [CrossRef]

26. Barrett, E.P.; Joyner, L.G.; Halenda, P.P. The determination of pore volume and area distributions in porous substances. J. Am. Chem. Soc. 1951, 73, 373-380. [CrossRef]

27. Liu, Q.S.; Zheng, T.; Wang, P.; Jiang, J.P.; Li, N. Adsorption isotherm, kinetic and mechanism studies of some substituted phenols on activated carbon fibers. Chem. Eng. J. 2010, 157, 348-356. [CrossRef]

28. Xi, X.; Guo, X. Preparation of bio-charcoal from sewage sludge and its performance on removal of $\mathrm{Cr}(\mathrm{VI})$ from aqueous solutions. J. Mol. Liq. 2013, 183, 26-30. [CrossRef]

29. APHA. Standard Methods for the Examination of Water and Wastewater, 20th ed.; American Public Health Association: Washington, DC, USA, 2001.

30. Zhang, D.; Huo, P.; Liu, W. Behavior of phenol adsorption on thermal modified activated carbon. Chin. J. Chem. Eng. 2016, 24, 446-452. [CrossRef]

31. Salame, I.I.; Bandosz, T.J. Role of surface chemistry in adsorption of phenol on activated carbons. J. Colloid Interface Sci. 2003, 264, 307-312. [CrossRef]

32. Gokce, Y.; Aktas, Z. Nitric acid modification of activated carbon produced from waste tea and adsorption of methylene blue and phenol. Appl. Surf. Sci. 2014, 313, 352-359. [CrossRef]

33. Álvarez-Torrellas, S.; Martin-Martinez, M.; Gomes, H.T.; Ovejero, G.; García, J. Enhancement of p-nitrophenol adsorption capacity through N2-thermal-based treatment of activated carbons. Appl. Surf. Sci. 2017, 414, 424-434. [CrossRef]

34. Agarwal, B.; Balomajumder, C.; Thakur, P.K. Simultaneous co-adsorptive removal of phenol and cyanide from binary solution using granular activated carbon. Chem. Eng. J. 2013, 228, 655-664. [CrossRef]

35. Feng, J.; Qiao, K.; Pei, L.; Lv, J.; Xie, S. Using activated carbon prepared from Typha orientails Presl to remove phenol from aqueous solutions. Ecol. Eng. 2015, 84, 209-217. [CrossRef]

36. Lagergren, S. About the theory of so-called adsorption of soluble substances. K. Sven. Vetensk. Handl. 1898, 24, 1-39.

37. Ho, Y.S.; McKay, G. Pseudo-second order model for sorption processes. Process Biochem. 1999, 34, 451-465. [CrossRef]

38. Ahmaruzzaman, M. Industrial wastes as low-cost potential adsorbents for the treatment of wastewater laden with heavy metals. Adv. Colloid Interface Sci. 2011, 166, 36-59. [CrossRef]

39. Xu, G.; Yang, X.; Spinosa, L. Development of sludge-based adsorbents: Preparation, characterization, utilization and its feasibility assessment. J. Environ. Manag. 2015, 151, 221-232. [CrossRef]

(C) 2020 by the authors. Licensee MDPI, Basel, Switzerland. This article is an open access article distributed under the terms and conditions of the Creative Commons Attribution (CC BY) license (http://creativecommons.org/licenses/by/4.0/). 